Anat. Inst. d. Med. Fak., Univ. Okayama (Vorstand : Prof. M. SEKI).

\title{
Beobachtung der mit hochfrequentem Schall behandelten Kollagenfasern im Elektronenmikroskop und Bestimmung ihrer sublichtmikroskopischen Strukturdichte auf färbe- rischem Wege.
}

\author{
超羙波を作用させた膠原線維の雪子頖微鏡内钼察とその光学 \\ 微視下構密度の染色法汇よる測定。
}

\begin{abstract}
Hakushi YASUDA 安田博志.
\end{abstract}
(Eingegangen am 30. März 1955.)

Bei der elektronoskopischen Untersuchung der Elemente des faserigen Gewebes zerfasert man es heute für gewöhnlich mit Hilfe der Ultraschallwellen. In einem vorhergegangenen Versuche habe ich (1954) beobachtet, wie die Ultraschallwellen die sublichtmikroskopische Struktur der Erythrocyten auflockern. Es liegt nahe daran zu denken, daß die Ultraschallwellen nicht nur das faserige Gewebe in einzelnen Mikrofibrillen zerfasern, sondern auch das molekulare Gefüge der Mikrofibrillen selbst mehr oder weniger stark zerstören.

\section{Material und Methode.}

Es wurden $0.5 \mathrm{~cm}$ lange Sehnenstücke aus dem Schwanz einer erwachsenen Maus auf dem Gefriermikrotom in $10 \mu$ dicke Schnitte zerlegt. Ein Teil der Schnitte wurde in einem Achatmörser mit 5 cc physiologischer Kochsalzlösung leicht 20 Minuten lang verrieben. Man übertrug die so erhaltene breiige Flüssigkeit in ein Reagenzglas, ließ es für 10 Minuten still stehen, nahm ein Tröpfchen der überstehenden Flüssigkeit auf eine befilmte Objektblende und trocknete es. Ebenso wurde aber auch zu 3 Tropfen von der überstehenden Flüssigkeit eine gleiche Menge einer 1\% igen Osmiumsäure zugesetzt und nach 2 Stunden wie oben auf einer anderen befilmten Objektblende aufgetrocknet. Man gab zu den Objektblenden, um die Kochsalzkristalle zu beseitigen, Tropfen destillierten Wassers und trocknete sie mit Filtrierpapier ab. Die Präparate wurden mit Chrom schräg bedampft und in einem HITACHI-Elektronoskop in 5000facher Vergrößerung photographiert.

Ein anderer Teil der Gefrierschnitte wurde ohne Verreiben im Achatmörser in $2 \mathrm{cc}$ physiologische Kochsalzlösung in einem harten Pyrexglasröhrchen von $0.5 \mathrm{~mm}$ Wanddicke, $20 \mathrm{~cm}$ Länge und $1.5 \mathrm{~cm}$ Kaliber gebracht. Das Glasröhrchen wurde im Beschallungsgerät so gestellt, daß 
seine Kuppe sich mit der Ölfläche berührt. Man hielt es immer in der Mitte des hervorspringenden Öles. Nach 10 minütigem Stehen wurde die überstehende Flüssigkeit, wie oben beschrieben ist, elektronoskopiert.

Es wurden weiterhin Sehnenstücke mit 10\%igem Formalin 48 Stunden fixiert und dann durch die obigen Verfahren untersucht.

Die der Einwirkung der Ultraschallwellen ausgesetzten Objekte wurden nach der LEACHschen Methode auf einem Deckglas aufgeklebt und, um die Veränderung ihrer sublichtmikroskopischen Strukturdichte zu bestimmen, nach der HEIDENHAINschen Azanmethode gefärbt. Zur genauen Vergleichung der Färbungsresultate färbte man die Objekte gleichzeitig und behandelte sie auch gleichzeitig nach.

Das Beschallungsgerät war der piezoelektorische S-200 Typus von SHIMAZU mit dem Schwingungszeuger von Bergkristallen. Der Schwingungskreis des Gerätes gehört zu dem HARTLEYschen; seine Schwingungsvakuumröhre ist das U. V. $204 \mathrm{~A}$ von TOSHIBA. Die Wellen sind von $710 \mathrm{kc}$. Der maximale einführende Strom beträgt $200 \mathrm{~mA}$ aus $2000 \mathrm{~V}$ Spannung. Bei unserem Versuch wurden einführende $200 \mathrm{~mA}$ aus $2000 \mathrm{~V}$ benutzt.

\section{Ergebnisse.}

\section{A. Befunde des Sehnengewebes ohne Beschallung.}

1. Elektronenbild.

Es seien hier vorerst die Mikrofibrillen aus dem nicht fixierten, nicht beschallten, aber im Achatmörser verriebenen Schwanzsehnengewebe besprochen. Jede schattendichte Querzone teilt sich in zwei kleinere schattendichte Zonen. In jeder schattenschwächeren Zone findet sich wiederum eine schmale schattendichtere Zone. Am formalinfixierten, im Achatmörser verriebenen Material sieht man die gleichen Mikrofibrillen wie oben.

2. Ultrastrukturdichte.

Die Fasern in den Gefrierschnitten der frischen Sehne erscheinen nach der Azanfärbung orangerot, aber sie färben sich nach der Fixierung mit Formalin violettblau.

\section{B. Befunde nach der Beschallung der Sehne.}

a) Nach 5minütiger Beschallung.

1. Elektronenbild.

Die Sehnenfasern werden in dieser Zeit noch nicht in die Mikrofibrillen zerlegt.

2. Ultrastrukturdichte.

Die Azanfärbung veranschaulicht schon eine Auflockerung des Gefüges der Fasern. Die nicht fixierten Fasern färben sich nun rotviolett (vor der Beschallung aber orange rot), und die mit Formalin fixierten stark 
blau (vor der Beschallung aber violettblau).

b) Nach 10minütiger Beschallung.

1. Elektronenbild.

Die nicht fixierten Sehnenfasern zerlegen sich in Mikrofibrillen. Die eine obere Mikrofibrille in Abb. 1 zeigt die gleiche Querzonierung

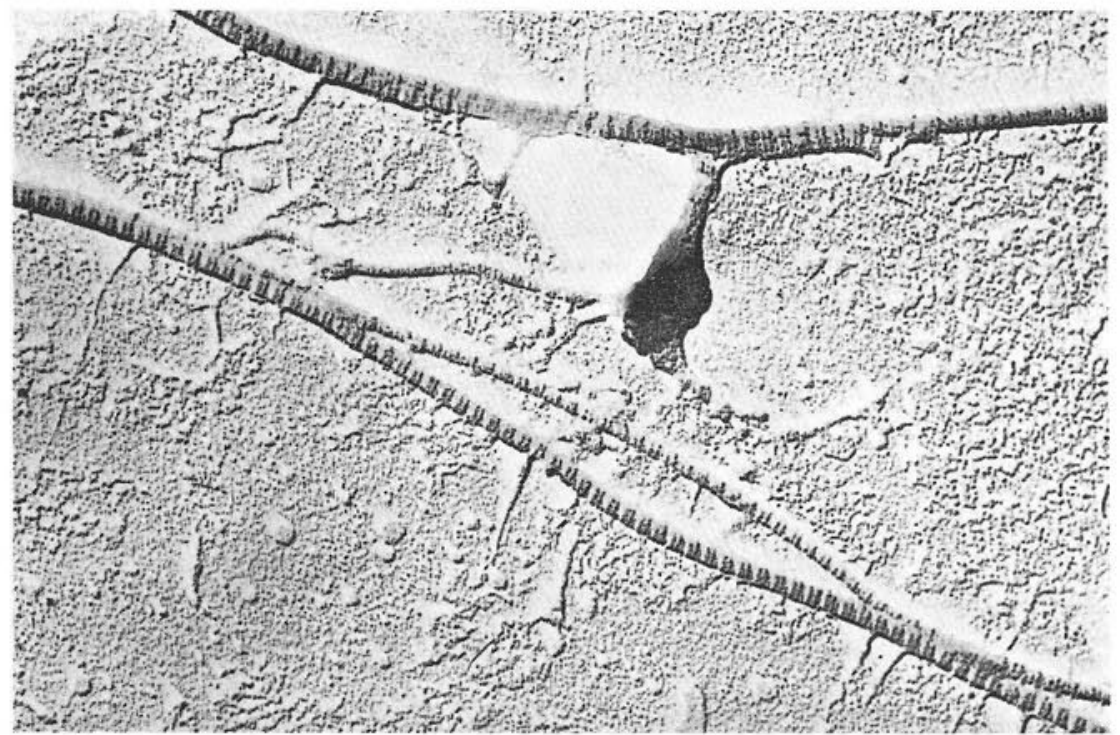

Abb. 1. Nicht fixierte Mikrofibrillen, nach 10minütiger Ultraschallwirkung. Mit Chrom schräg bedampft. Die eine oben liegende Mikrofibrille sieht wie normal aus. In den unten liegenden zwei Mikrofibrillen vermindern sich die Querzonen. 35, $000 \times$.

wie vor der Beschallung, die unteren zwei Mikrofibrillen verlieren vielerorts die schmale Querzone in ihrer schattenschwächeren Zone.

In Abb. 1 sieht man ferner hier und da zur schattendichten Querzone der Mikrofibrille senkrecht stehende Elementarfibrillen oder Monomolekülketten, worauf schon SEKI (1952) und KAJIKAWA und SUMITA (1953) aufmerksam gemacht haben. SEKI hat ihre Entstehung durch die Annahme der Richtwirkung von Dipolen erklärt.

Die mit Formalin fixierten Kollagenfasern werden in dieser Zeit noch nicht in Mikrofibrillen zerlegt.

2. Ultrastrukturdichte.

Nach 5minütiger Beschallung werden die nicht fixierten Kollagenfasern nach der Azanmethode, wie erwähnt, rotviolett gefärbt, nach 10minütiger Beschallung aber violettblau. Der vermehrte blaue Ton deutet auf eine Auflockerung des Gefüges hin. Die mit Formalin fixierten 
Sehnenfasern werden noch immer dunkel blau gefärbt.

c) Nach 20minütiger Beschallung.

1. Elektronenbild.

Die Veränderung der nicht fixierten Mikrofibrillen ist fast die gleiche wie vorher. Die mit Formalin fixierten zeigen noch keine weitere Veränderung.

2. Ultrastrukturdichte.

Nach der Azanmethode färben sich die Fasern wie vorher.

d) Nach 1stündiger Beschallung.

1. Elektronenbild.

Die frischen Mikrofibrillen zeigen, wie in Abb. 2 dargestellt wird, keine Strukturperiode mehr. Vielerorts werden sie abgebaut, wobei die Moleküle oder Micellen von $2-5 \mathrm{~m} / \ell$ Diameter auseinander gehen.

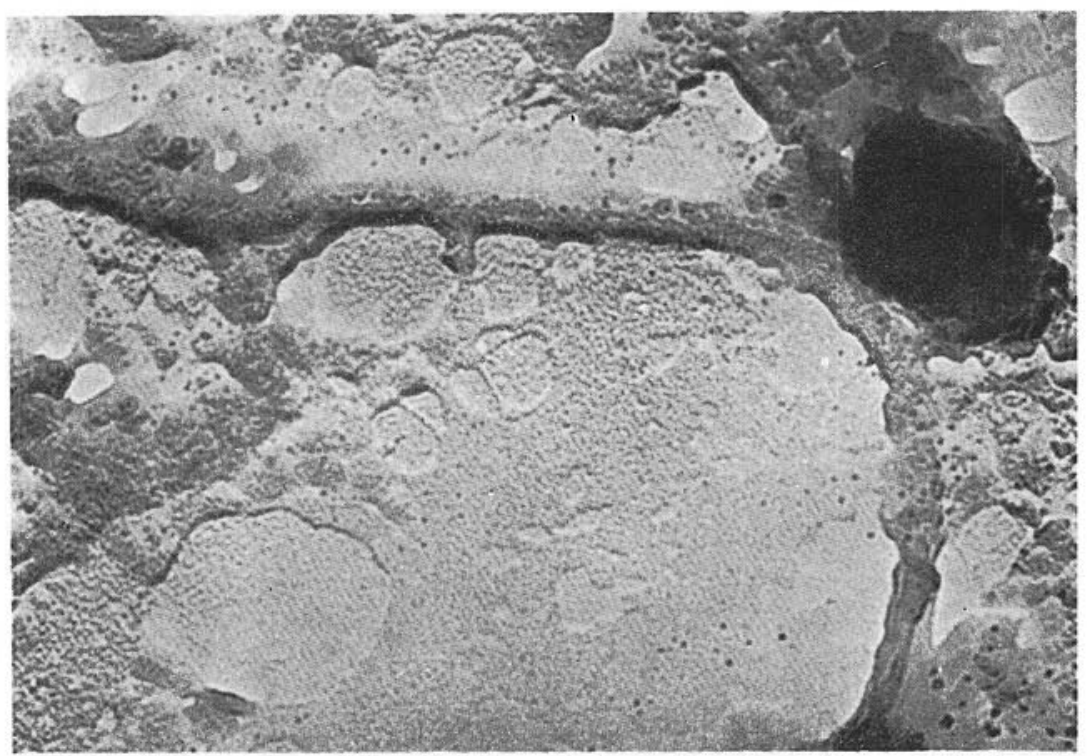

Abb. 2. Nicht fixierte Mikrofibrille, nach 1stündiger Beschallung. Mit Chrom schräg bedampft. Die Strukturperiode ist verschwunden. Die Mikrofibrille zerfällt vielerorts. $50,000 \times$.

Bei vielen von den mit Formalin fixierten Mikrofibrillen verschwindet die periodische Querzonierung (Abb. 3).

2. Ultrastrukturdichte.

Die Färbbarkeit der nicht fixierten und fixierten Mikrofibrillen nach der Azanmethode bleibt wie vorher. 


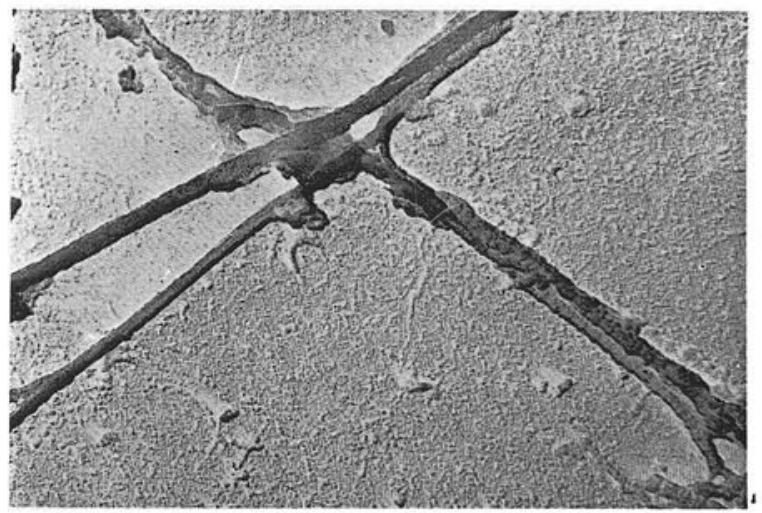

Abb. 3. Mit Formalin fixierte Mikrofibrillen, nach 1stündiger Beschallung. Mit Chrom schräg bedampft. Die Strukturperiode der Mikrofibrillen ist stellenweise verschwunden. $25,000 \times$.

\section{e) Nach 1.5stündiger Beschallung.}

Die nicht fixierten Mikrofibrillen verändern sich stark. In Abb. 4 sind zwei zerfallene Mikrofibrillen dargestellt. In der Umgebung gibt es reichlich Teilchen, welche offenbar Zerfallprodukte der Mikrofibrillen sind.

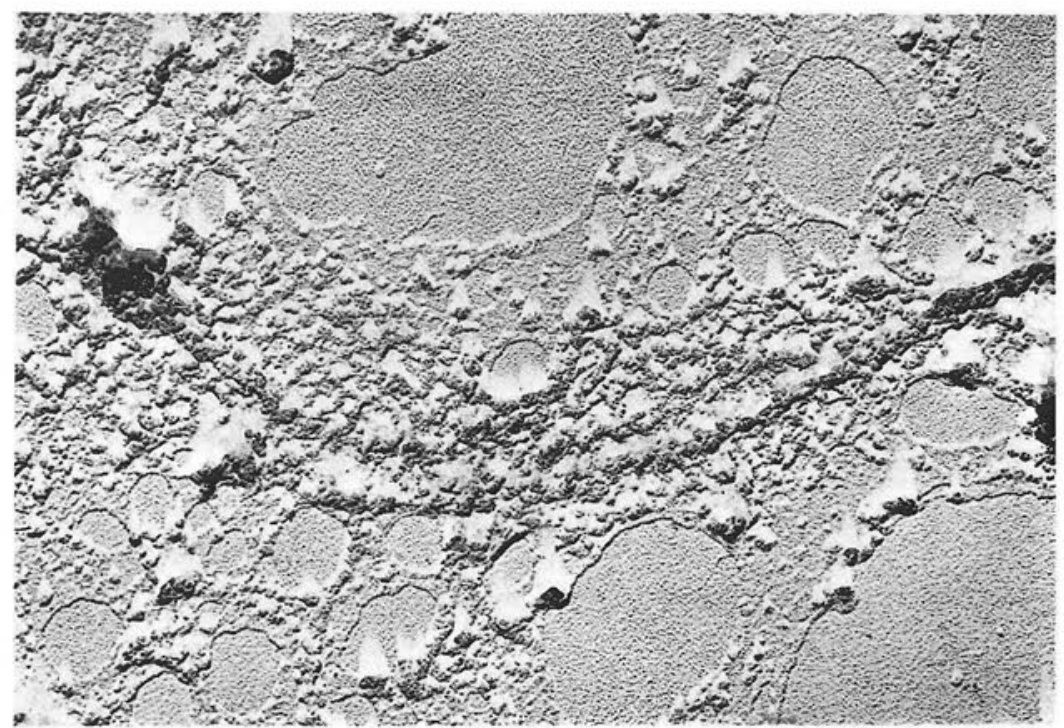

Abb. 4. Zerfallen der nicht fixierten Mikrofibrillen, nach 1.5stündiger Beschallung. Mit Chrom schräg bedampft. 25,000x. 


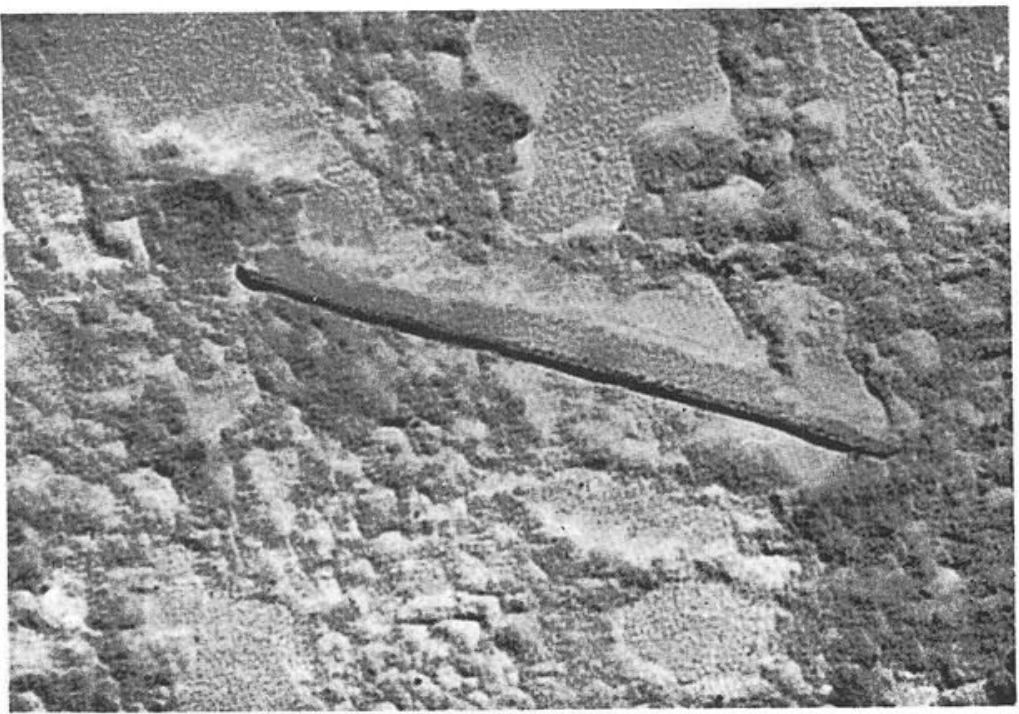

Abb. 5. Ein Bruchstück einer nicht fixierten Mikrofibrillen, nach 2stündiger Beschallung. Mit Chrom schräg bedampft. 50,000 $\times$.

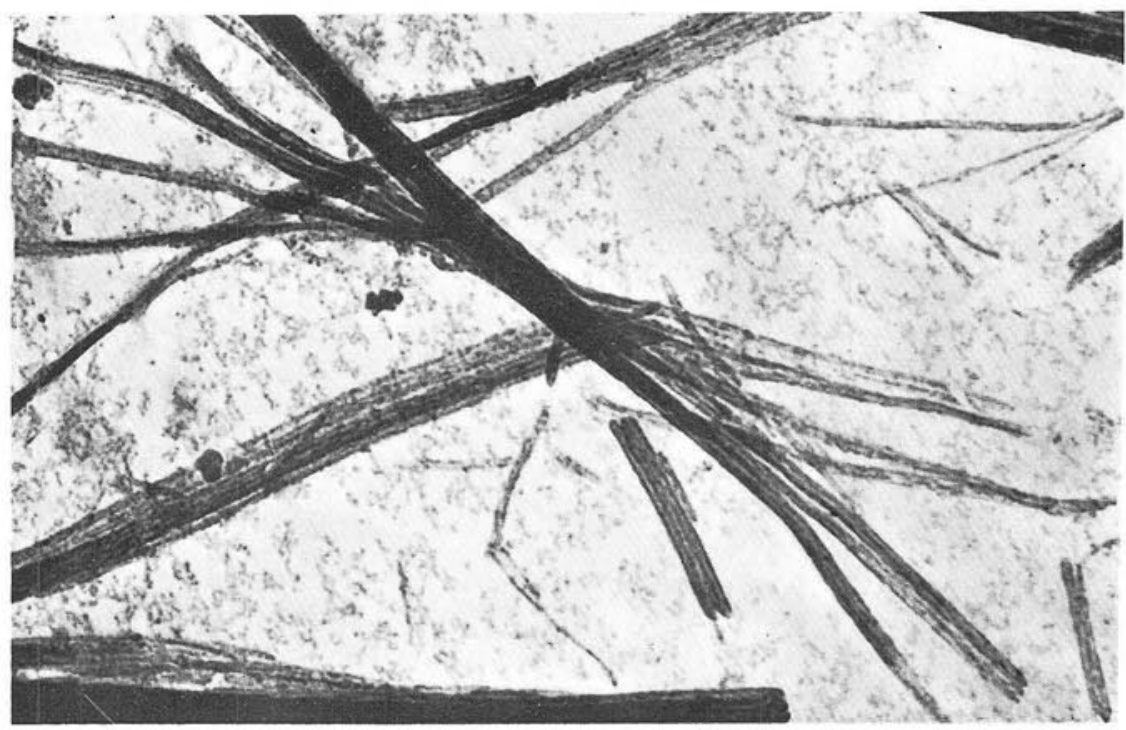

Abb. 6. Nicht fixierte Mikrofibrillen, nach 2stündiger Beschallung. Die Strukturperiode der Mikrofibrillen ist verschwunden. Die Mikrofibrillen zerlegen sich in Elementarfibrillen. 50,000 $\times$. 


\section{f) Nach 2stündiger Beschallung.}

Im Bruchstück der Mikrofibrille in Abb. 5 sieht man keine Strukturperiode. In der Umgebung finden sich zerfallene granuläre Produkte reichlich.

In Abb. 6 sind die Mikrofibrillen auf dem Wege der Zerlegung in Elementarfibrillen (in singuläre Molekülketten).

\section{g) Nach 2.5stündiger Beschallung.}

Der Abb. 7 liegen die 2.5 Stunden lang beschallten, nicht fixierten Sehnenstücke zugrunde. Die Mikrofibrillen zerlegen sich in mehrere Elementarfibrillen, welche wiederum in einzelne Moleküle oder Micellen von $2-5 \mathrm{~m} \mu$ Diameter zerfallen.

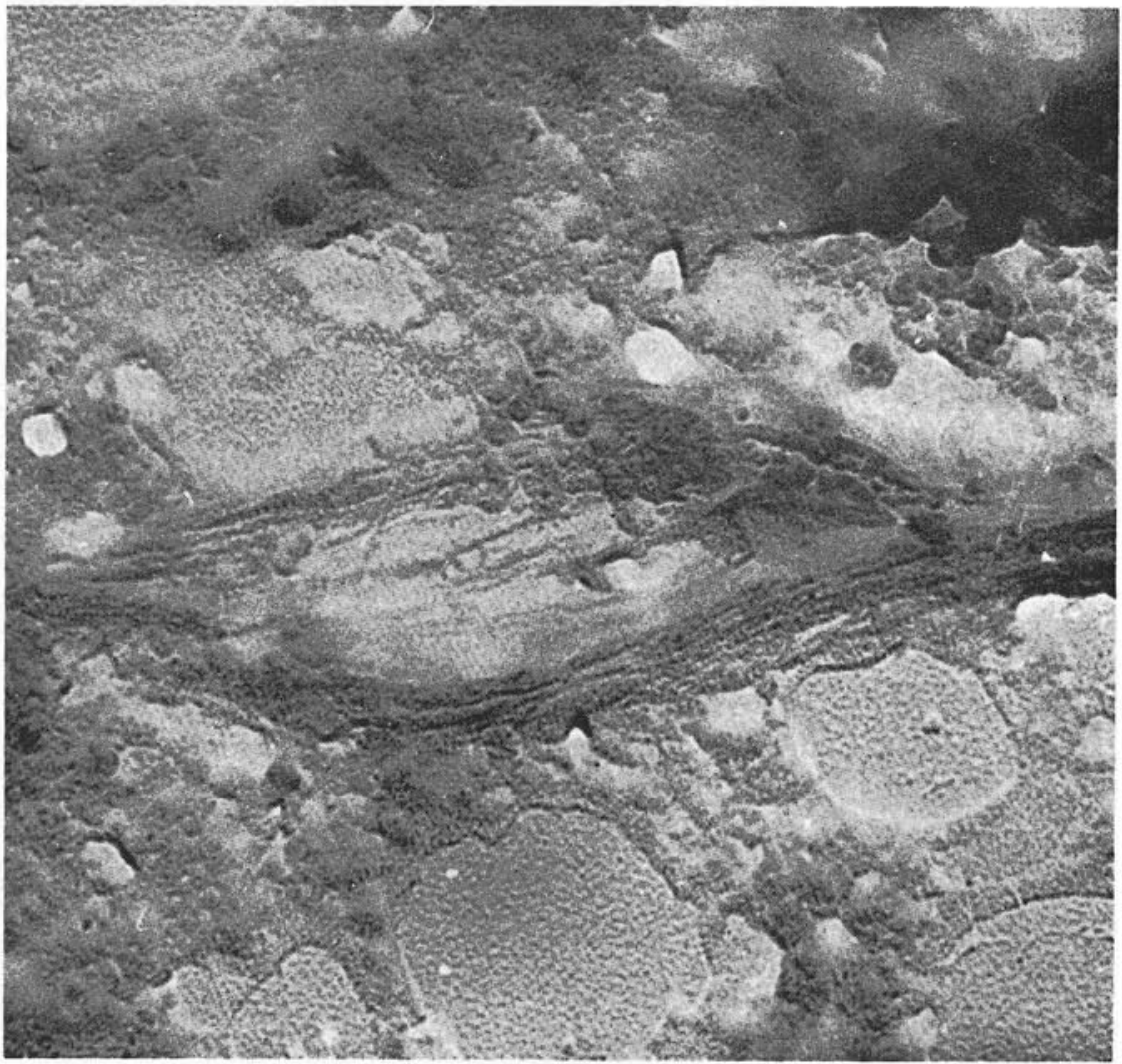

Abb. 7. Nicht fixierte Mikrofibrillen, nach 2.5stündiger Beschallung. Mit Chrom schräg bedampft. Die Mikrofibrillen zerlegen sich in Elementarfibrillen, welche wiederum in Moleküle oder Micellen zerfallen. 50,000 ×. 
Die Abb. 8 ist ein merkwürdiges Elektronenbild eines nicht fixierten Sehnenstückes nach 2.5stündiger Beschallung, das aber darauf mit 1\% iger

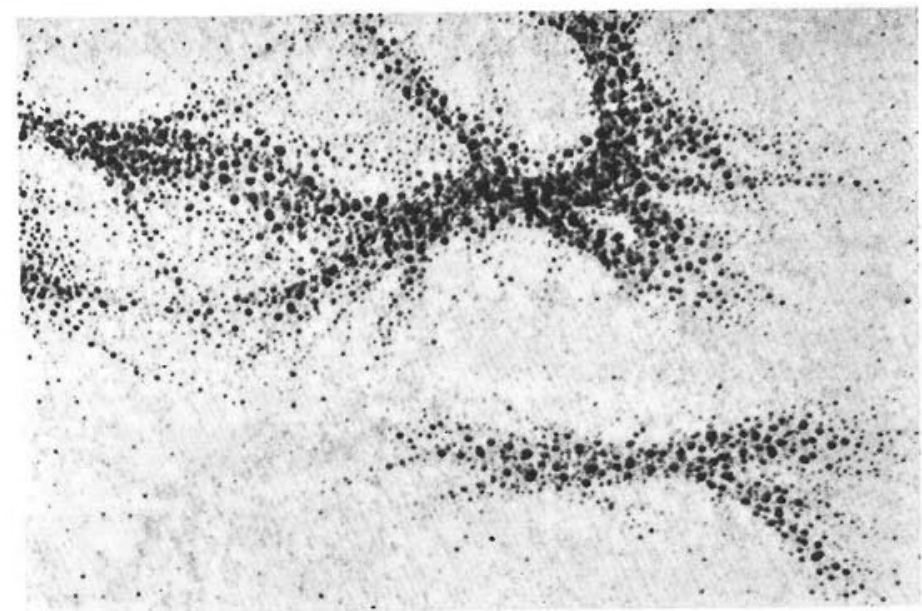

Abb. 8. Nicht fixiertes Sehnengewebe, nach 2.5stündiger Beschallung mit Osmiumtetroxyd behandelt. Die dunklen tropfenförmigen Gebilde bestehen vielleicht hauptsächlich aus fettigen Substanzen. 40,000 $\times$.

Osmiumsäure behandelt wurde. Das Osmiumtetroxyd wird bekanntlich an den stark reduzierend wirkenden Gewebeselementen reduziert und lagert sich dort als unlösliches Osmiumdioxyd ab. Unter den tierischen Gewebesubstanzen wirken Fett und Lipoide am stärkesten reduzierend. Meines Erachtens wurden Fett und Lipoide bei der Zersetzung der kollagenen Fibrillen durch lang dauernde Ultraschallwirkung demaskiert, verschmolzen miteinander und bildeten kuglige Tropfen, an welche das für Elektronenstrahlen undurchläßige Osmium sich ablagerte. Zur Unterstützung dieser Annahme soll ein Studium (1955) über die demaskierende Wirkung des Ultraschalls auf das Fett und die Lipoide in den Milchkügelchen folgen.

\section{Zusammenfassung.}

Die frischen kollagenen Fibrillen der Mausschwanzsehne werden durch 1.0minütige Ultraschallwirkung schon teilweise in Mikrofibrillen zerlegt, die mit Formalin fixierten aber erst nach 20 Minuten. Die periodische Struktur der so isolierten Mikrofibrillen ist die gleiche wie die der durch Verreiben im Achatmörser isolierten. Jede Periode teilt sich nämlich in 6 kleine Zonen.

Verlängert sich die Beschallungsdauer, so verschwindet die Strukturperiode der nicht fixierten Mikrofibrillen. Sie teilen sich in Elementarfibrillen, Ketten von Molekülen oder Micellen, und zerfallen schließlich 
in einzelne Moleküle oder Micellen von 2-5 m/^ Diameter. Die Erscheinuug ist umgekehrt zu der Beobachtung von SEKI $(1952,1955)$ bei der Mikrofibrillenbildung. Nach ihm bildet sich eine Elementarfibrille durch Verbindung der Moleküle oder Micellen in Längsrichtung, und durch gleichzeitige und wiederholte Zusammenlagerung mehrerer Elementarfibrillen entsteht eine dickere Mikrofibrille.

Bei der Azanfärbung benutzt man kleinmolekulares Goldorange G, mittelgroß molekulares, rotes Azokarmin und noch größer molekulares Anilinblau. Die unbehandelten Gefrierschnitte der frischen Sehnenfasern färben sich nach der Azanmethode bei Anwendung der Farbstofflösungen in gewissen Konzentrationen orangerot. Nach der 5minütiger Ultraschallwirkung werden sie rotviolett und nach der 10minütiger violettblau oder blau färbbar. Die Färbung in abnehmendem Rot und zunehmendem Blau zeigt eine Herabsetzung der Strukturdichte. Die mit Formalin fixierten Fasern färbten sich immer violettblau. Ihr Strukturdichte wurde durch die Beschallung nicht verändert.

Durch die Ultraschallwirkung entstehen aus den kollagenen Fasern zahlreiche tropfenförmige Gebilde, vielleicht von fettiger und lipoider Natur.

\section{肉容自 抄。}

新鮮な二十日鼠の尾腱の凍綕切片に超音波を作用させれば，ホルマリン 固定のものの埸合の約 2 分 1 の時間にて原線維が微原線維に分離せられ始 める。

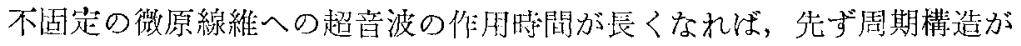
消失し，微原線維が分子または微粘子の単一の連鎖なる素原線維に分れ， 遂には個々の径 2-5 m $\mu$ の分子または微椟子飞分れる。

アツォン染色によると，不固定の㳀線維は超音波の作用によって橙赤よ り亦紫，遂炕紫青または青に染るよ5飞なる，即ち次第飞大分子の染料飞 よく染るようになり，分子構造の疎化与ることが証明せられる。しかるに ホルマリンにて固定された即では線維は常に紫青飞染められ，超構密度の 繁化することが認められない。

超音波の作用により膠原線維から多くの淌状物体が生じ，これは多分脂 肪と類脂質の性質を持つ。

\section{Literatur.}

Kajikawa, K. a. Y. Sumita : Electron microscopic studies on the connective tissue. I. Structure of normal loose connective tissue fibers and their 
formation. Tr. Soc. path. jap. 42 (1953). - Seki, M. : Molekularhistologische Studien über die Elementar- und Mikrofibrillen des Kollagens mit besonderer Berücksichtigung der Dipolrichtwirkung bei ihrer Neubildung und Entwicklung. Arch. hist. jap. 3 (1952). - Molekularhistologische Studien über die Elementarund Mikrofibrillen des Kollagens. II. Nähere Beobachtung ïber die periodische Querzonierung der kollagenen Mikrofibrillen. Arch. hist. jap. 7 (1954). Yasuda, H.: Elektronoskopische Beobachtung der mit hochfrequentem Schall behandelten fixierten Erythrocyten und Bestimmung ihrer Ultrastrukturdichte auf färberischem Wege. Arch. hist. jap. 7 (1954). 